\title{
Estimation of Time Factors in Radiotherapy for Head and Neck Cancer with Auto-regressive Integrated Moving Average Model After Dashboard Launching
}

\section{Wei-lun Huang}

Kaohsiung Veterans General Hospital

Wen-shan Liu

Kaohsiung Veterans General Hospital

Po-chun Chen

Pingtung Christian Hospital

Hsiu-min Chen

Kaohsiung Veterans General Hospital

Ching-Chih Lee ( $\nabla$ hematcd2@hotmail.com )

Kaohsiung Veterans General Hospital

Research article

Keywords: Oral cavity cancer, Radiation treatment time, Survival, Nudge-based intervention

Posted Date: October 30th, 2020

DOl: https://doi.org/10.21203/rs.3.rs-98056/v1

License: (c) (i) This work is licensed under a Creative Commons Attribution 4.0 International License.

Read Full License 


\section{Abstract}

\section{Background:}

Radiotherapy (RT) time factors are well-established prognostic factor for oral squamous cell carcinoma (OSCC). We investigated the association of a nudge-based intervention for clinicians and time factors in a referral cancer center.

\section{Methods:}

We examined 89 OSCC patients receiving RT at our center between 2015 and 2017. A dashboard displaying dose/time variation between planned values and actual values was used in the electronic medical record since 2015. The association between planned and actual time factors [radiotherapy treatment time (RTT), OP to RT interval (ORI), and treatment package time (TPT)] and time period was analyzed with linear regression after dashboard launching. Autoregressive Integrated Moving Average (ARIMA) model was further used to establish the best-fit model for the intervals of the RT therapy process.

\section{Results:}

After dashboard implementation, the RT duration shortened from 48 days to 38.8 days ( $p$ value $=0.013$ ), waiting from 35.2 days to 33.5 days ( $p$ value $=0.002$ ), and total treatment duration from 80.8 days to 76 days ( $p$ value $<0.001$ ). Estimation of time factors with ARIMA found that the ARIMA model with an autoregression term of 1 , difference of 1 , and a moving average term of 1 , or ARIMA $(1,1,1)$ model, could both describe and predict the days of RTT, ORI, and TPT well. The mean absolute percentage error (MAPE) for the models were $4.2 \%, 4.7 \%$, and $2.1 \%$ respectively, which implied the models were reasonable for use in the hospital setting.

\section{Conclusions}

This study demonstrated that an electronic dashboard with alerts for RT interval can significantly shorten RTT for OSCC patients. Furthermore, AIRMA $(1,1,1)$ provided an estimation of time factors.

\section{Background}

Oral squamous cell carcinoma (OSCC) incidence rates continue to increase in many countries, as people continue tobacco and betel quid use [1]. Radiotherapy (RT) is administered as a primary treatment for cases unable to tolerate or unsuited for surgery, or as adjuvant therapy after primary surgery to improve loco-regional control and survival [2]. However, despite intensified and multidisciplinary therapy, local, regional, and distant failure rates have remained high over the last decade [3].

The established prognostic treatment factors which impact the outcomes of RT for oral cavity cancer include concurrent chemotherapy therapy, total dose, and daily fraction size [4, 5]. The RT time factor also 
plays a key role, with radiotherapy treatment time (RTT), surgery to radiotherapy interval (ORI), and treatment package time (TPT) all shown to affect overall survival, cause-specific survival, local-regional relapse-free survival, and metastasis-free survival in patients with oral cavity cancer [6-9]. Longer RTT, ORI, and TPT decrease the likelihood of cure for patients receiving definitive or postoperative RT.

Interventions to shorten the treatment duration are desperately needed. The behavioral economics concept of libertarian paternalism, or nudge, proposed by Thaler and Sunstein, involves the use of incentives and disincentives to "nudge" consumers toward a desired behavior [10]. As applied in healthcare, this principle involves providing a dashboard of outcomes to help physicians more accurately steer the course of patient care. Examples of its successful use in healthcare include programs at the hospital of the University of Pennsylvania that improved health care delivery, cancer screening, and influenza vaccination rates [11-13]. University Hospitals Bristol used nudge-based interventions with displaying tidal volume on the dashboard to help physicians significantly reduce the delivered tidal volumes in ventilated Intensive Care Unit patients $[14,15]$.

To examine whether the presentation of prolonged RTT to staff can reduce RTT, we retrospectively analyzed the RTT after electronic dashboard display of the RTT of oral cavity cancer patients receiving RT at a department of Radiation Oncology over a 2-year period. We further sought to estimate the time factors using an autoregressive integrated moving average (ARIMA) model.

\section{Methods}

This retrospective study was undertaken in the department of Radiation Oncology at Kaohsiung Veteran General Hospital, Taiwan, a cancer referral center. All information relating to patient receipt of RT (including initial note, complete notes, minutes of case-discussion meetings, and data from the treatment planning system) was stored in one database (IBM DB2 OS/390 8.2). Patients receiving postoperative or definite RT/chemoradiotherapy for oral cavity cancer were included in the study. Patients receiving RT for palliation were excluded.

The RT electronic medical record (EMR) system was built in the healthcare information system of Kaohsiung Veteran Hospital starting in 2014. The RT EMR system consisted of initial note, complete summary, and new patient's conference record. The information on patients receiving RT in these medical records is stored by each patient's medical record number and divided into three types: CTINNO, CTINXML, and CTINCON (Fig. 1). CTINNO was designed to store the data used for analysis and calculation. Descriptive sentences, such as present illness and comments from conferences, are stored in CTINXML. Electronic signature data are stored in CTINCON.

To improve the quality of RT treatment, six treatment indicators were established: guideline compliance rate, conference approval rate, on-time completion rate of the initial note, on-time completion rate of the complete summary, the difference between the planned dosage and the prescribed dosage, and the difference between the planned RT interval and the actual RT interval. Completion of the initial note was to be done one week after the simulation, while the complete summary was to be completed in three 
weeks after the end of RT. In the weekly new patient conference, all members of the Radiation Oncology department discuss whether or not the RT plan complies with the guidelines and approve the final treatment plan. The difference between the planned dosage and the prescribed dosage should be less than $5 \%$ of the planned dosage. Meanwhile, the difference between the planned RT interval and the actual RT interval should be less than $10 \%$ of the planned RT interval. The system extracts the data, including an optional checkbox in the new patient conference, the RT simulation date in the initial note, and the RT start and end date in the complete note (from CTINNO), and the date of the electronic signature (from CTICON), then calculates the indicators for the achievement rate of six treatments.

An electronic dashboard was introduced in 2015 to provide information transparency. Authorized users, including surgeons, medical oncologists, physician assistants, and cancer case managers, can specify a date range to display. The electric dashboard summarizes and presents the guideline compliance rate, the conference approval rate, the on-time completion rate of the initial note, the on-time completion rate of the complete note, the difference between the planned dosage and the prescribed dosage, and the difference between the planned RT interval and the actual RT interval (Fig. 2).

ORI was defined as the interval between the day of curative surgery and the start of adjuvant RT. TPT was defined as the summation of RTT and ORI for those who underwent surgery and adjuvant RT or chemoradiotherapy.

\section{Statistical analysis}

The distribution of patient, tumor, and treatment characteristics were analyzed. The impact of the use of a nudge-based dashboard on RTT, ORI, and TPT was explored with linear regression. The ARIMA model was used to establish the best-fit model for the intervals of the RT therapy process [16]. For the ARIMA model parameters, we determined the best-fit model by evaluating the association of the predicted accuracy of the identified model with the fit indices. We used coefficient of determination (R2), the mean absolute percentage error (MAPE), mean absolute error (MAE), and Bayesian information criterion (BIC) to measure and quantify the quality of fit. Except for R2, lower values of the other measures will indicate a better fit of the data. All statistical analyses were performed using IBM SPSS Statistics for Windows, Version 20.0. (IBM Corp., Armonk, NY, USA). A two-sided test with a P value of $<0.05$ was set as representing statistical significance. All confidence intervals (Cls) were stated at the $95 \%$ level.

\section{Results}

In all, 89 OSCC patients were recruited. The mean age was 55 years (standard deviation, 12) and 84 patients (94\%) were male. Of these, 63 patients underwent surgery and adjuvant RT/chemoradiotherapy, and 26 patients received RT/chemoradiotherapy alone (Table 1). Fully $90 \%$ of patients had advanced stage disease. 
Table 1

Demographic data of oral cancer patients

\begin{tabular}{|c|c|c|}
\hline & Oral cancer & Oral cancer treated with surgery \\
\hline & $n=89$ & $n=63$ \\
\hline \multicolumn{3}{|l|}{ Age } \\
\hline Mean \pm SD & $55 \pm 12$ & $54 \pm 11$ \\
\hline \multicolumn{3}{|l|}{ Gender } \\
\hline Female & $5(6 \%)$ & $5(8 \%)$ \\
\hline Male & $84(94 \%)$ & $58(92 \%)$ \\
\hline \multicolumn{3}{|l|}{ Differentiation } \\
\hline 1 & $13(15 \%)$ & $10(16 \%)$ \\
\hline 2 & $66(74 \%)$ & $48(76 \%)$ \\
\hline 3 & $10(11 \%)$ & $5(8 \%)$ \\
\hline Chemotherapy & $23(26 \%)$ & $18(29 \%)$ \\
\hline Surgery & $63(71 \%)$ & \\
\hline \multicolumn{3}{|l|}{ Treatment } \\
\hline Only RT & $21(24 \%)$ & \\
\hline CRT & $5(6 \%)$ & \\
\hline RT + Surgery & $45(51 \%)$ & $45(71 \%)$ \\
\hline CRT + Surgery & $18(20 \%)$ & $18(29 \%)$ \\
\hline \multicolumn{3}{|c|}{ cT classification } \\
\hline 1 & $6(7 \%)$ & $6(9 \%)$ \\
\hline 2 & $16(18 \%)$ & $10(16 \%)$ \\
\hline 3 & $6(7 \%)$ & $4(6 \%)$ \\
\hline 4 & $61(68 \%)$ & $43(68 \%)$ \\
\hline \multicolumn{3}{|c|}{ cN classification } \\
\hline 0 & $33(37 \%)$ & $25(40 \%)$ \\
\hline 1 & $11(13 \%)$ & $8(13 \%)$ \\
\hline
\end{tabular}

Abbreviation: SD, standard deviation; RT, radiotherapy; CRT: chemoradiotherapy. 


\begin{tabular}{|lll|}
\hline & Oral cancer & Oral cancer treated with surgery \\
\hline 2 & $43(48 \%)$ & $29(46 \%)$ \\
\hline 3 & $2(2 \%)$ & $1(2 \%)$ \\
\hline Overall clinical stage & & \\
\hline I & $3(3 \%)$ & $3(5 \%)$ \\
\hline II & $6(7 \%)$ & $5(8 \%)$ \\
\hline III & $9(10 \%)$ & $6(10 \%)$ \\
\hline Follow-up months & $71(80 \%)$ & $49(78 \%)$ \\
\hline Mean \pm SD & $7 \pm 4$ & $7 \pm 4$ \\
\hline Cigarette & $67(75 \%)$ & $48(76 \%)$ \\
\hline Alcohol & $61(69 \%)$ & $43(68 \%)$ \\
\hline Betel & $55(62 \%)$ & $39(62 \%)$ \\
\hline Abbreviation: SD, standard deviation; RT, radiotherapy; CRT: chemoradiotherapy.
\end{tabular}

Table 2

Time factors related to radiotherapy

\begin{tabular}{|c|c|c|c|c|c|c|c|c|c|c|c|}
\hline & $\mathrm{n}$ & 2015 & & 2016 & & & & 2017 & & & \\
\hline Time & & Q3 & Q4 & Q1 & Q2 & Q3 & Q4 & Q1 & Q2 & Q3 & Q4 \\
\hline $\begin{array}{l}\text { RT treatment } \\
\text { time (RTT) }\end{array}$ & 89 & 48.0 & 45.6 & 47.8 & 46.4 & 48.4 & 46.0 & 50.7 & 43.1 & 45.1 & 38.8 \\
\hline $\begin{array}{l}\text { OP to RT interval } \\
\text { (ORI) }\end{array}$ & 63 & $\mathrm{~N} / \mathrm{A}$ & 35.2 & 38.4 & 36.0 & 37.1 & 33.0 & 30.2 & 32.5 & 27.0 & 33.5 \\
\hline $\begin{array}{l}\text { Treatment } \\
\text { package time } \\
(\mathrm{TPT})\end{array}$ & 63 & $\mathrm{~N} / \mathrm{A}$ & 80.8 & 84.7 & 82.4 & 85.6 & 77.5 & 81.0 & 76.1 & 74.0 & 76.0 \\
\hline
\end{tabular}

The electric dashboard was initiated in July, 2015 (Fig. 2). The effect of dashboard use on the RTT is illustrated in Fig. 3. At the beginning of the study period (July-December 2015), the mean RTT was 48 days. At the end of analysis (July-December 2017), the mean RTT was 38.8 days. Linear regression analysis showed that the RTT was shortened over time (beta coefficient $-0.7, \mathrm{p}$ value $=0.013$ ). For those 
receiving surgery and adjuvant therapy, the ORI was 35.2 days and the TPT was 80.8 days at the beginning. At the end of the study, both the ORI and the TPT had decreased significantly $(p=0.002$ and < 0.001 , respectively). During the two-year follow-up period after the beginning of using a dashboard to monitor the quality of cancer treatment, the RTT, ORI, and TPT were reduced significantly.

In order to establish a prediction model for RT time factors, an ARIMA model was built. The observational plot showed no seasonal influence; we therefore restricted our attention to the non-seasonal ARIMA model. Fit indices showed that the ARIMA model with an auto-regression term of 1 , difference of 1 , and a moving average term of 1 , or ARIMA $(1,1,1)$, yielded the best fit of all models for RTT, ORI, and TPT (Table 3, Fig. 4, 5, 6, and supplementary table for ARIMA equation). We found that the AR(1) coefficient of -0.92 was significant $(p<0.05)$, but not the MA $(1)$ coefficient of -0.13 . The results indicated that the RT therapy time on the previous day was a significant predictor. We found the same result for TPT (Table 4). The R2 for the models of RTT, ORI, and TPT were $53 \%, 72 \%$, and $81 \%$, respectively. In addition, the MAPE for the same models were $4.2 \%, 4.7 \%$, and $2.1 \%$, respectively, which implied that the models were reasonable for use in the research hospital setting. 
Table 3

Comparison of various selected ARIMA models

\begin{tabular}{|c|c|c|c|c|}
\hline Model & $\mathrm{R}^{2}$ & MAPE & MAE & BIC \\
\hline \multicolumn{5}{|c|}{ Radiotherapy treatment time (RTT) } \\
\hline $0,1,1$ & 0.10 & 5.47 & 2.51 & 2.96 \\
\hline $1,0,1$ & 0.27 & 4.76 & 2.12 & 3.00 \\
\hline $1,1,1$ & 0.53 & 4.24 & 1.93 & 2.71 \\
\hline $2,1,2$ & 0.38 & 4.24 & 1.95 & 2.99 \\
\hline \multicolumn{5}{|c|}{ Operation to radiotherapy interval (ORI) } \\
\hline $0,1,1$ & 0.71 & 4.86 & 1.62 & 1.91 \\
\hline $1,0,1$ & 0.50 & 6.08 & 2.02 & 2.79 \\
\hline $1,1,1$ & 0.72 & 4.71 & 1.56 & 2.28 \\
\hline $2,1,2$ & 0.59 & 5.63 & 1.86 & 2.64 \\
\hline \multicolumn{5}{|c|}{ Treatment package time (TPT) } \\
\hline $0,1,1$ & 0.73 & 2.58 & 2.07 & 2.52 \\
\hline $1,0,1$ & 0.41 & 4.09 & 3.26 & 3.69 \\
\hline $1,1,1$ & 0.81 & 2.10 & 1.68 & 2.61 \\
\hline $2,1,2$ & 0.73 & 2.72 & 2.77 & 2.94 \\
\hline
\end{tabular}

Abbreviation: $\mathrm{R}^{2}$, Coefficient of determination; MAPE, the mean absolute percentage error; MAE, mean absolute error; BIC, Bayesian information criterion. 
Table 4

Parameter estimates for the ARIMA $(1,1,1)$ models using the algorithm of maximum likelihood

\begin{tabular}{|c|c|c|c|c|c|}
\hline Outcomes & Parameter & Estimate & SE & t value & $P$ value \\
\hline \multirow[t]{2}{*}{ Radiotherapy treatment time } & $\mathrm{AR}(1)$ & -0.92 & 0.24 & -4.48 & 0.007 \\
\hline & $\mathrm{MA}(1)$ & -0.13 & 0.56 & -0.23 & 0.827 \\
\hline \multirow[t]{2}{*}{ Operation to radiotherapy interval } & $\mathrm{AR}(1)$ & -0.09 & 0.68 & -0.14 & 0.897 \\
\hline & $\mathrm{MA}(1)$ & 0.98 & 11.98 & 0.08 & 0.938 \\
\hline \multirow[t]{2}{*}{ Treatment package time } & $\operatorname{AR}(1)$ & -0.78 & 0.28 & -2.78 & 0.039 \\
\hline & $\mathrm{MA}(1)$ & 0.97 & 12.00 & 0.08 & 0.939 \\
\hline
\end{tabular}

\section{Discussion}

We evaluated the association between the RTT, ORT, and TPT and the use of an electric dashboard to monitor the quality of cancer care in a cancer center in southern Taiwan. Once clinicians began using the electric dashboard, the RTT, ORT, and TPT of the patients decreased gradually. Use of the nudge-based strategy of an EMR-based dashboard shortened the RTT, ORI, and TPT of patients in our hospital, which could in turn to reduce the recurrence rate. In our analysis, the ARIMA $(1,1,1)$ model was well able to describe and predict the days of RTT, ORI, and TPT.

Our hospital launched an electric dashboard to monitor the quality of cancer care in 2015 . The electric dashboard, which consisted of six radiation therapy quality indexes, gave the physicians information on the guideline compliance rate, conference approval rate, on-time completion rate of the initial note, ontime completion rate of the complete summary, the difference between the planned dosage and the prescribed dosage, and the difference between the planned RT interval and the actual RT interval. The strengths of using an electric dashboard to monitor cancer treatment in Radiation Oncology include the automatic calculation of the above-mentioned indicators through the hospital information system, a brief summary of each indicator, and access to any member of the healthcare team. The goals of our electric dashboard were to give feedback to physicians on the quality of radiation treatment for all patients. Due to its innovation in improving the quality of cancer treatment, this system won a safety and quality certification in Taiwan in 2015. Furthermore, we used ARIMA to establish a prediction model for the relevant RT time factors. ARIMA is a statistical model with distinct advantages over regression techniques in analyzing time-series data. This model has been widely adopted in economics, earth science, and epidemiology [17-19]. However, its application in RTT, ORI, or TPT has not yet been reported. Therefore, we decided to construct an adequate model to analyze and forecast the impact of the electronic dashboard using ARIMA methodology. Data analysis showed that the ARIMA $(1,1,1)$ model was 
able to describe and predict the days of RTT, ORI, or TPT with low MAPE, which meant highly accurate forecasting [20].

OSCC is notorious for its high recurrence rate and poor prognosis [3,21,22]. The mainstay of treatment for OSCC is surgery with or without adjuvant therapy. In our series, $71 \%$ of patients with OSCC underwent surgery. Among those receiving RT or chemoradiotherapy, the time impact of RT/chemoradiotherapy, including RTT, ORI, and TPT, was explored. Prolonged RTT, e.g., more than 8 weeks, has been associated with inferior outcomes in those with head and neck cancer (Hazard Ratio, 1.25; 95\% Confidence Interval, 1.11-1.5) [23]. This phenomenon was robust for those with post-operative RT or definite RT. A longer treatment time may lead to tumor repopulation, which in turn results in worse outcomes. TPT of $<100$ days was associated with improved outcomes in patients with head and neck cancer treated with surgery and adjuvant RT [24]. Similar results were reported by Ang et al. in a randomized trial, which showed that patients with a longer operation to radiation interval and longer RTT (total > 13 weeks) had higher rates of loco-regional recurrence $(P=0.001)[6]$.

Because the time factors of RT are associated with prognosis for patients with head and neck cancer, clinicians should seek to shorten the wait time, RTT, or both. Toustrup et al. revealed that a fast track strategy with a full-time case manager, multidisciplinary tumor board, and higher priority for head and neck cancer examination slots could dramatically shorten the time between the initial visit and the start of curative treatment, from 57 to 29 days [25]. Van Huizen et al. found that multidisciplinary first-day consultation might shorten the days needed for diagnostic procedures and the days to the start of the first treatment in patients with head and neck cancer [26]. They concluded that the introduction of a multidisciplinary first-day consultation, including specialists of different departments and the use of coordinating nurses, could improve treatment quality. However, the study did not analyze RT duration or total treatment time.

Recently, nudge-based intervention healthcare has gained wider attention. Different concepts or combinations of nudge-based strategy have been applied to reduce healthcare cost or increase vaccination rates. Within the EMR, adding active choice in a clinic visit for adults eligible for influenza vaccination brought an increase of $6.6 \%$ for vaccinations, or a $37 \%$ relative increase [13]. Using a default design in medication prescription to favor the generic medication over the brand-name medicine increased the overall generic prescribing from $75-98 \%$ within 7 months [27]. The long-term effect of default design has also been reported [28]. Further nudge-based strategies such as incentive and feedback through social networks for weight loss have also been found feasible [29]. The major strategy of our use of an electric dashboard to increase the quality of radiation oncology care in our hospital was feedback, which efficiently shortened the radiation time in our cohort. However, nudge-based strategy might not always work. In one study, displaying Medicare-allowable fees for inpatient laboratory tests in the EMR with a nudge-based feedback strategy did not significantly change the ordering behavior of physicians [30]. 
There were some limitations in our series. First, the total number of OSCC patients included in this study was 95 patients, which resulted in large standard errors. Our observation deserves a future large cohort or a longer observation period to validate this phenomenon. Second, the limited observation duration of our series prevented long-term follow up of disease outcomes, such as tumor recurrence or survival rates. Third, the optimal RT duration for head and neck cancer is approximate 6-7 weeks in conventional fractionation, since the recommended dose is 60-70 Gy. Therefore, the decrease of RT duration is limited when the average RT duration approaches the optimal time. The main outcomes of this study were the association between use of an electric dashboard and the reduction in RTT, ORI, and TPT. We plan to in the future analyze the association of optimal RT time and dosage.

\section{Conclusion}

This study revealed that a nudge-based intervention derived from behavioral economics could shorten the RTT, ORI, and TPT in patients with OSCC receiving RT. All the above-mentioned indices are evidenceproven prognosticators for OSCC survival. Establishment of a dashboard to indicate treatment quality, which can provide feedback to the healthcare staff, may improve cancer treatment outcomes. Our analysis also found that the ARIMA $(1,1,1)$ model was well able to describe and predict the days of RTT, $\mathrm{ORI}$, and TPT.

\section{Abbreviations}

OSCC: Oral cavity squamous cell carcinoma; RTT: Radiotherapy treatment time; ORI: Surgery to radiotherapy interval; TPT: Treatment package time; OS: Overall survival; CSS: Cause-specific survival; LRFS: Local-regional relapse-free survival; MFS: Metastasis-free survival; ARIMA: Autoregressive integrated moving average; EMR: Electronic medical record; MAPE: Mean absolute percentage error; MAE: mean absolute error; BIC: Bayesian information criterion

\section{Declarations}

\section{Ethics approval and consent to participate}

This study was approved by the Institutional Review Board of Kaohsiung Veteran General Hospital, Taiwan (IRB: VGHKS16-CT3-05). The informed consent was waived because all the identifying information was removed from the data set before analysis.

\section{Consent for publication}

Not applicable.

\section{Availability of data and materials}

According to the IRB in our institute, the access to data was not allowed in this study. 
Competing interests

The authors declare that they have no competing interests

Funding

This study was partly supported by Kaohsiung Veterans General Hospital (Grant No.: VGHKS108-170).

\section{Authors' contributions}

WLH and CCL were responsible for the collection of data. WLH and CCL drafted the manuscript. HMC were responsible for the data analysis. WSL and PCC reviewed and edited the manuscript. All authors read and approved the final manuscript.

\section{Acknowledgements}

The authors expressed their appreciation to the Department of Medical Education and Research \& Research Center of Medical Informatics in Kaohsiung Veterans General Hospital for inquiries and assistance in data processing.

\section{References}

1. Simard EP, Torre LA, Jemal A: International trends in head and neck cancer incidence rates: differences by country, sex and anatomic site. Oral oncology 2014, 50(5):387-403.

2. Cooper JS, Pajak TF, Forastiere AA, Jacobs J, Campbell BH, Saxman SB, Kish JA, Kim HE, Cmelak AJ, Rotman $\mathrm{M}$ et al: Postoperative concurrent radiotherapy and chemotherapy for high-risk squamouscell carcinoma of the head and neck. The New England journal of medicine 2004, 350(19):19371944.

3. Carvalho AL, Nishimoto IN, Califano JA, Kowalski LP: Trends in incidence and prognosis for head and neck cancer in the United States: a site-specific analysis of the SEER database. International journal of cancer 2005, 114(5):806-816.

4. Dahlke S, Steinmann D, Christiansen H, Durisin M, Eckardt A, Wegener G, Bremer M, Meyer A: Impact of Time Factors on Outcome in Patients with Head and Neck Cancer Treated with Definitive Radio (Chemo) Therapy. in vivo 2017, 31(5):949-955.

5. Herrmann T, Baumann M: [Prolongation of latency or overall treatment time by unplanned radiation pauses. The clinical importance of compensation]. Strahlentherapie und Onkologie : Organ der Deutschen Rontgengesellschaft [et al] 2005, 181(2):65-76.

6. Ang KK, Trotti A, Brown BW, Garden AS, Foote RL, Morrison WH, Geara FB, Klotch DW, Goepfert H, Peters LJ: Randomized trial addressing risk features and time factors of surgery plus radiotherapy in advanced head-and-neck cancer. International journal of radiation oncology, biology, physics 2001, 51(3):571-578. 
7. Cheng YJ, Tsai MH, Chiang CJ, Tsai ST, Liu TW, Lou PJ, Liao CT, Lin JC, Chang JTC, Tsai MH et al: Adjuvant radiotherapy after curative surgery for oral cavity squamous cell carcinoma and treatment effect of timing and duration on outcome-A Taiwan Cancer Registry national database analysis. Cancer Medicine 2018, 7(7):3073-3083.

8. Langendijk JA, de Jong MA, Leemans CR, de Bree R, Smeele LE, Doornaert P, Slotman BJ:

Postoperative radiotherapy in squamous cell carcinoma of the oral cavity: the importance of the overall treatment time. International journal of radiation oncology, biology, physics 2003, 57(3):693700.

9. Parsons JT, Mendenhall WM, Stringer SP, Cassisi NJ, Million RR: An analysis of factors influencing the outcome of postoperative irradiation for squamous cell carcinoma of the oral cavity. International journal of radiation oncology, biology, physics 1997, 39(1):137-148.

10. Thaler RH, Sunstein CR: Libertarian paternalism. American economic review 2003, 93(2):175-179.

11. Patel MS, Volpp KG, Asch DA: Nudge Units to Improve the Delivery of Health Care. The New England journal of medicine 2018, 378(3):214-216.

12. Patel MS, Volpp KG, Small DS, Wynn C, Zhu J, Yang L, Honeywell S, Jr., Day SC: Using active choice within the electronic health record to increase physician ordering and patient completion of highvalue cancer screening tests. Healthcare (Amsterdam, Netherlands) 2016, 4(4):340-345.

13. Patel MS, Volpp KG, Small DS, Wynne C, Zhu J, Yang L, Honeywell S, Jr., Day SC: Using Active Choice Within the Electronic Health Record to Increase Influenza Vaccination Rates. Journal of general internal medicine 2017, 32(7):790-795.

14. Bourdeaux CP, Birnie K, Trickey A, Thomas MJ, Sterne J, Donovan JL, Benger J, Brandling J, Gould $\mathrm{TH}$ : Evaluation of an intervention to reduce tidal volumes in ventilated ICU patients. British journal of anaesthesia 2015, 115(2):244-251.

15. Bourdeaux CP, Thomas MJ, Gould TH, Malhotra G, Jarvstad A, Jones T, Gilchrist ID: Increasing compliance with low tidal volume ventilation in the ICU with two nudge-based interventions: evaluation through intervention time-series analyses. BMJ open 2016, 6(5):e010129.

16. Box GEP, Tiao GC: Intervention Analysis with Applications to Economic and Environmental Problems. Journal of the American Statistical Association 1975, 70(349):70-79.

17. Junior PR, Salomon FLRr, Pamplona EdO: ARIMA: An Applied Time Series Forecasting Model for the Bovespa Stock Index. Applied Mathematics 2014, Vol.05No.21:9.

18. Shirvani A, Moradi F, Moosavi AA: Time series modelling of increased soil temperature anomalies during long period. International Agrophysics 2015, 29(4):509-515.

19. Juang WC, Huang SJ, Huang FD, Cheng PW, Wann SR: Application of time series analysis in modelling and forecasting emergency department visits in a medical centre in Southern Taiwan. BMJ open 2017, 7(11):e018628.

20. Montaño J, Palmer A, Sesé A, Cajal B: Using the R-MAPE index as a resistant measure of forecast accuracy. Psicothema 2013, 25:500-506. 
21. Ko C, Citrin D: Radiotherapy for the management of locally advanced squamous cell carcinoma of the head and neck. Oral diseases 2009, 15(2):121-132.

22. Pulte $D$, Brenner $H$ : Changes in survival in head and neck cancers in the late 20th and early 21 st century: a period analysis. The oncologist 2010, 15(9):994-1001.

23. Shaikh T, Handorf EA, Murphy CT, Mehra R, Ridge JA, Galloway TJ: The Impact of Radiation Treatment Time on Survival in Patients With Head and Neck Cancer. International journal of radiation oncology, biology, physics 2016, 96(5):967-975.

24. Rosenthal DI, Liu L, Lee JH, Vapiwala N, Chalian AA, Weinstein GS, Chilian I, Weber RS, Machtay M: Importance of the treatment package time in surgery and postoperative radiation therapy for squamous carcinoma of the head and neck. Head \& neck 2002, 24(2):115-126.

25. Toustrup K, Lambertsen K, Birke-Sorensen H, Ulhoi B, Sorensen L, Grau C: Reduction in waiting time for diagnosis and treatment of head and neck cancer - a fast track study. Acta oncologica (Stockholm, Sweden) 2011, 50(5):636-641.

26. van Huizen LS, Dijkstra PU, van der Laan B, Reintsema H, Ahaus KTB, Bijl HP, Roodenburg JLN: Multidisciplinary first-day consultation accelerates diagnostic procedures and throughput times of patients in a head-and-neck cancer care pathway, a mixed method study. BMC health services research 2018, 18(1):820.

27. Patel MS, Day SC, Halpern SD, Hanson CW, Martinez JR, Honeywell S, Jr., Volpp KG: Generic Medication Prescription Rates After Health System-Wide Redesign of Default Options Within the Electronic Health Record. JAMA internal medicine 2016, 176(6):847-848.

28. Olshan D, Rareshide CAL, Patel MS: Longer-Term Durability of Using Default Options in the Electronic Health Record to Increase Generic Prescribing Rates. Journal of general internal medicine 2018.

29. Ryskina K, Jessica Dine C, Gitelman Y, Leri D, Patel M, Kurtzman G, Lin LY, Epstein AJ: Effect of Social Comparison Feedback on Laboratory Test Ordering for Hospitalized Patients: A Randomized Controlled Trial. Journal of general internal medicine 2018, 33(10):1639-1645.

30. Sedrak MS, Myers JS, Small DS, Nachamkin I, Ziemba JB, Murray D, Kurtzman GW, Zhu J, Wang W, Mincarelli $D$ et al: Effect of a Price Transparency Intervention in the Electronic Health Record on Clinician Ordering of Inpatient Laboratory Tests: The PRICE Randomized Clinical Trial. JAMA internal medicine 2017, 177(7):939-945.

\section{Figures}






Figure 1

The framework of information of patients receiving radiotherapy in these medical records divide into three type: CTINNO, CTINXML, and CTINCON. 


\begin{tabular}{|c|c|c|c|c|c|}
\hline \multicolumn{6}{|c|}{ Treatment Quality Indicator for 9 (ICD9) } \\
\hline Nasopharyngeal cancer & $147,147.9$ & Breast cancer & 174 & Esophageal cancer & 150 \\
\hline Rectal cancer & 154 & Lung cancer & 162 & Cervical cancer & 180 \\
\hline Lymphoma & 201,202 & Prostate cancer & 185 & & \\
\hline Oral cavity cancer & $\begin{array}{l}140,141,143,144, \\
145\end{array}$ & $\begin{array}{l}\text { Head and neck cancer } \\
\text { (hypopharyngeal cancer) }\end{array}$ & $\begin{array}{l}148 \\
148.0 / 1 / 2 / 3 / 8 / 9\end{array}$ & $\begin{array}{l}\text { Head and neck cancer } \\
\text { (oropharyngeal cancer) }\end{array}$ & $\begin{array}{l}146, \\
146.0 \sim 146.9\end{array}$ \\
\hline \multicolumn{6}{|c|}{ 2018-12-19 2019-01-15 中文绸面 } \\
\hline Data source & Simulation date & RT end date & \multicolumn{3}{|c|}{ Content of dashboard } \\
\hline \multirow{2}{*}{$\begin{array}{l}\text { New patients } \\
\text { conference record }\end{array}$} & Check(ALL) & Check(ALL) & \multirow{2}{*}{\multicolumn{2}{|c|}{$\begin{array}{l}\text { 1. Report of guidelines compliance rate } \\
\text { A. Compliance to guideline } \\
\text { B. Approval at new patients conference }\end{array}$}} & \\
\hline & Check(Short) & Check(Short) & & & \\
\hline \multirow{2}{*}{ Initial note } & Check(ALL) & Check(ALL) & \multirow{2}{*}{\multicolumn{3}{|c|}{$\begin{array}{l}\text { 2. Report of initial note completion rate } \\
\text { Completion of initial note after RT start in } 1 \text { week }\end{array}$}} \\
\hline & Check(Short) & Check(Short) & & & \\
\hline \multirow{2}{*}{$\begin{array}{l}\text { Complete note } \\
\& \text { initial note }\end{array}$} & Check(ALL) & Check(ALL) & \multirow{2}{*}{\multicolumn{3}{|c|}{$\begin{array}{l}\text { 3. Report of RT dose and interval analysis } \\
\text { A. Difference between planning dosage and prescribed } \\
\text { dosage less than } 5 \% \\
\text { B. Difference between planning RT interval and RT } \\
\text { *Planning RT interval = (planning fractions of RT/5) } \times 7\end{array}$}} \\
\hline & Check(Short) & Check(Short) & & & \\
\hline \multirow{2}{*}{ Complete note } & Check(ALL) & Check(ALL) & \multirow{2}{*}{\multicolumn{3}{|c|}{$\begin{array}{l}\text { 4. Report of complete note completion rate } \\
\text { Completion of complete note after RT end in } 3 \text { weeks }\end{array}$}} \\
\hline & Check(Short) & Check(Short) & & & \\
\hline
\end{tabular}

\section{Figure 2}

The electric dashboard

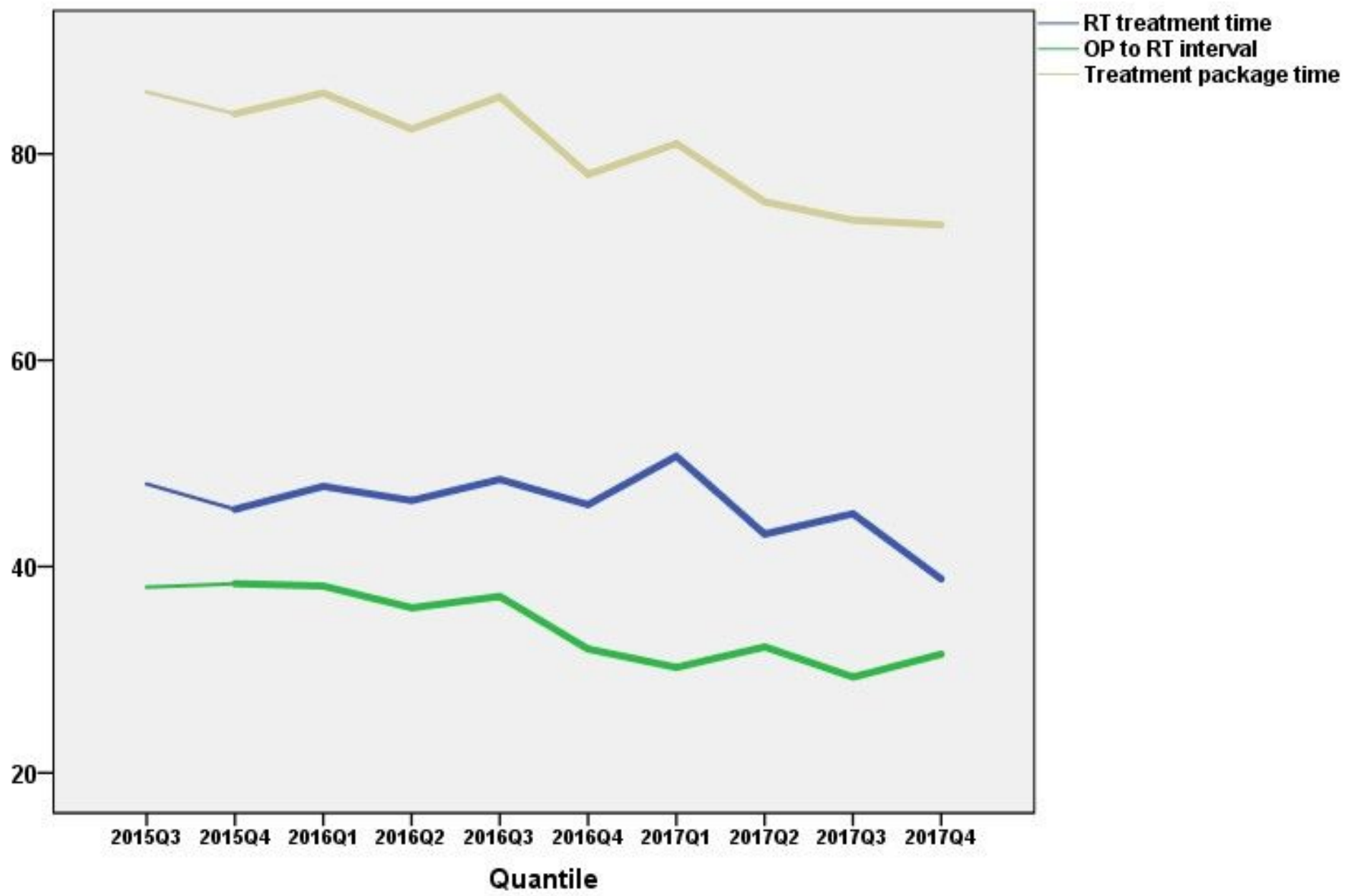

Figure 3 
Time series plot of RT treatment time, OP to RT interval, and treatment package time from July 2015 to December 2017. Abbreviation: RT, radiotherapy; OP, operation.

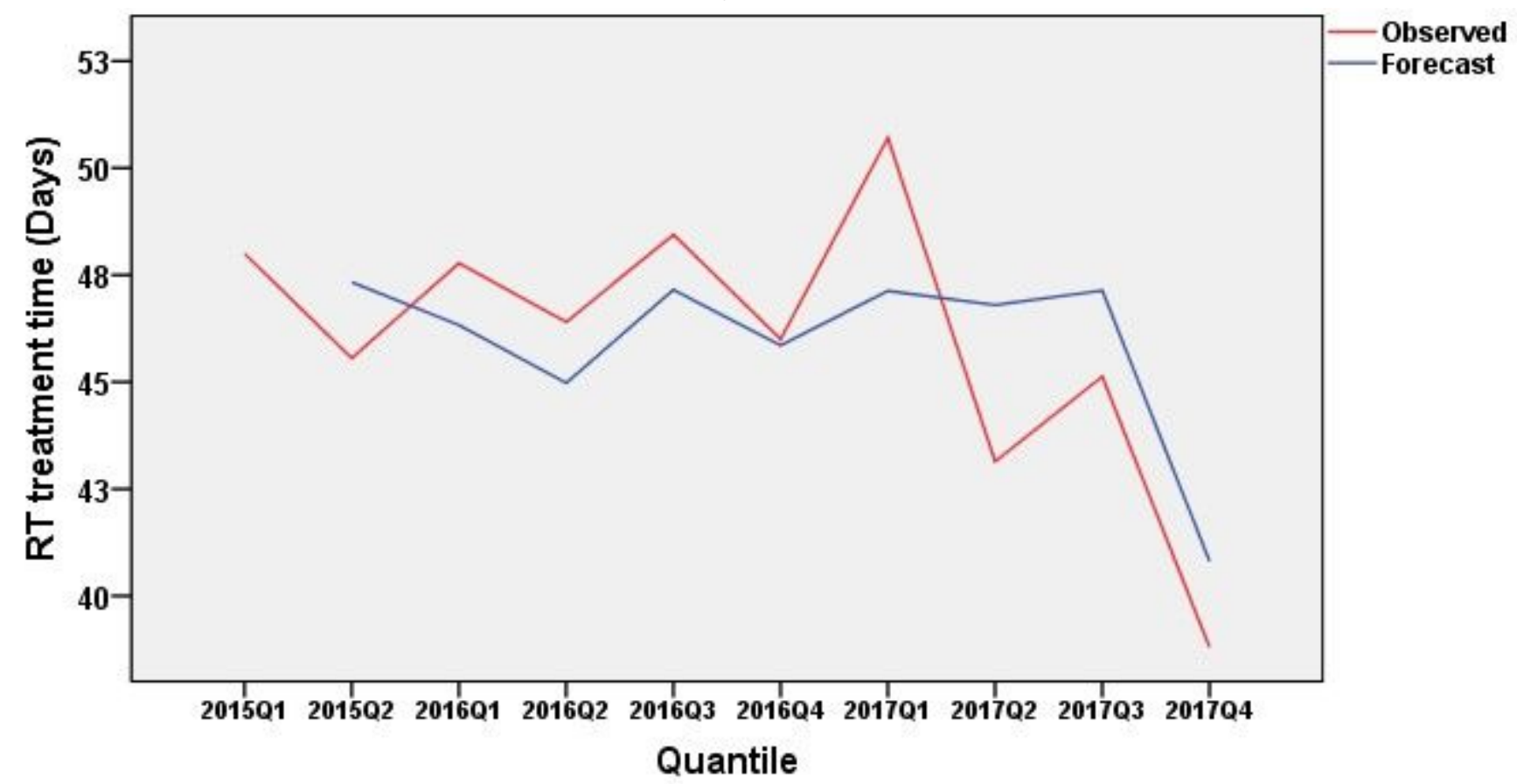

Figure 4

Predicted and actual number of the RT treatment time for the ARIMA model $(1,1,1)$ Abbreviation: RT, radiotherapy.

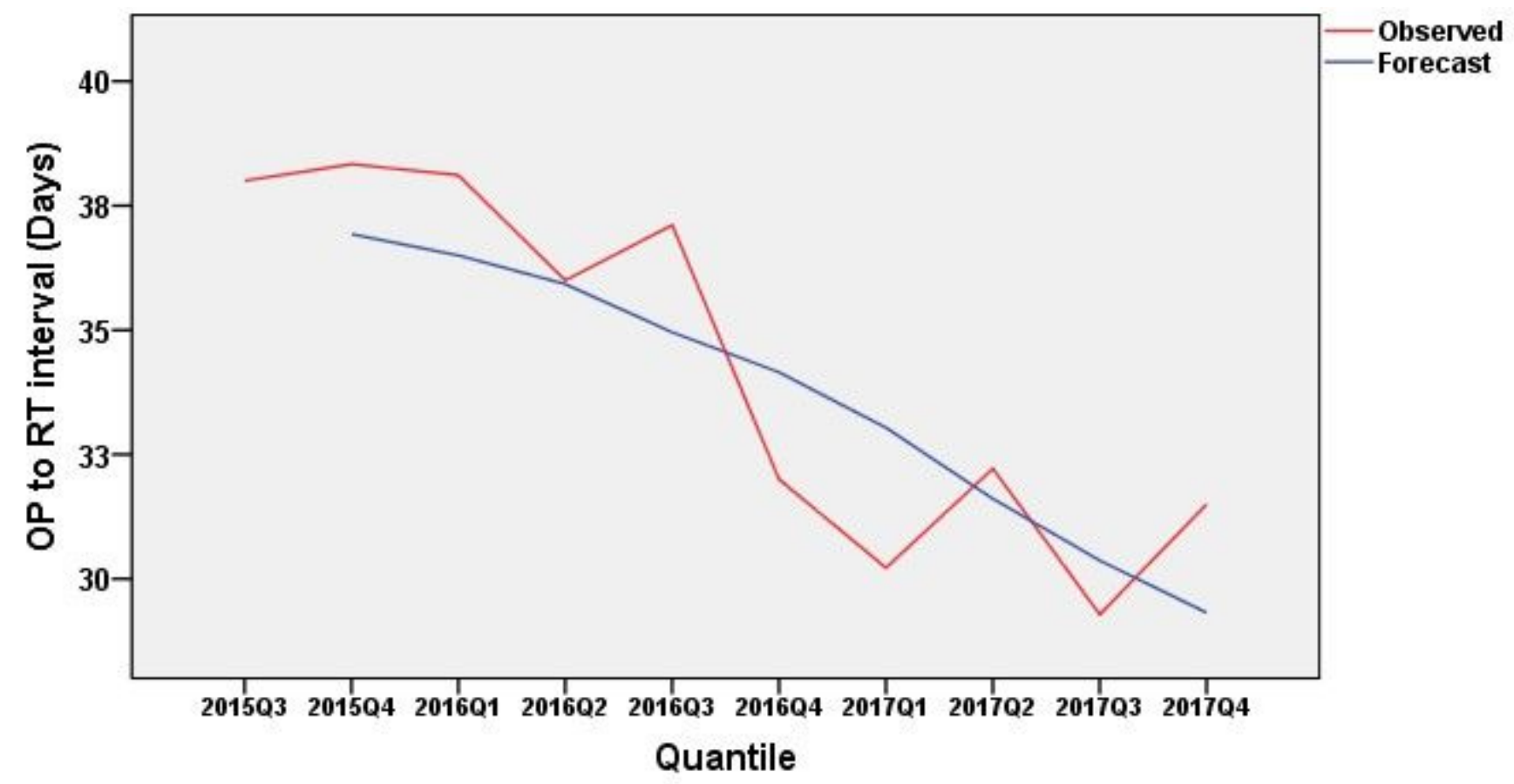

Figure 5 
Predicted and actual number of the OP to RT interval for the ARIMA model $(1,1,1)$ Abbreviation: RT, radiotherapy; OP, operation.

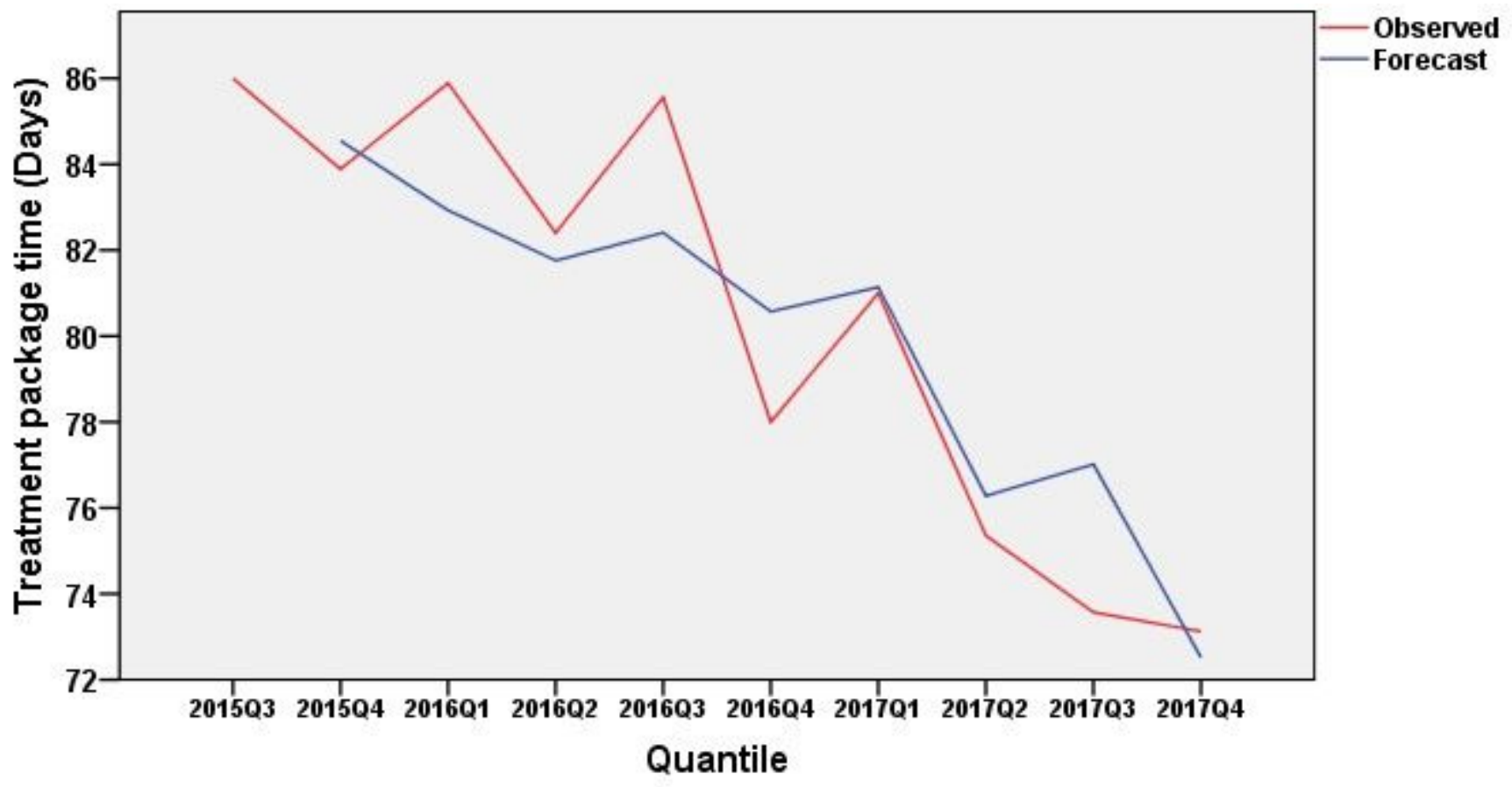

Figure 6

Predicted and actual number of the treatment package time for the ARIMA model $(1,1,1)$

\section{Supplementary Files}

This is a list of supplementary files associated with this preprint. Click to download.

- Supplementarytable.docx 